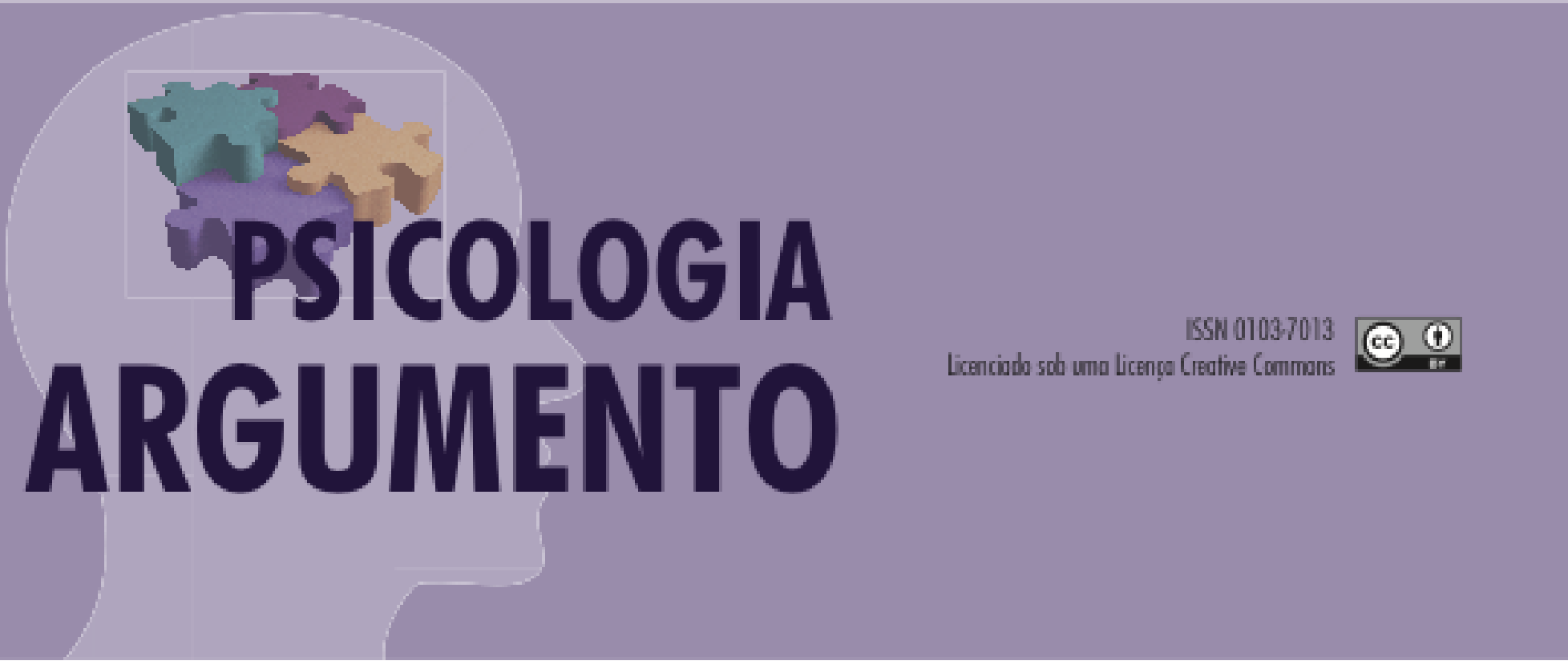

doi: 10.7213/psicol.argum.34.084.AO01

\title{
Conflitos interpessoais e desenho animado: Um es- tudo sobre os estilos de resolução predominantes
}

Interpersonal conflicts and cartoons: A study of the predominant styles of resolution

Dilian Martin Sandro de Oliveira[a], Alessandra de Morais ${ }^{[b]}$

[a] Doutoranda em Psicologia Escolar e Desenvolvimento Humano pela Universidade de São Paulo (USP), São

Paulo, SP - Brasil, e-mail: dilianvip@yohoo.com.br

[b] Doutora em Educação pelo Programa de Pós-Graduação em Educação e Professora Assistente do Departamento de Psicologia da Educação, Faculdade de Filosofia e Ciências, Universidade Estadual Paulista (UNESP), Marília, SP - Brasil, e-mail: alemorais.shimizu@gmail.com.

Pesquisa financiada pela Fundação de Amparo à Pesquisa do Estado de São Paulo (FAPESP)

\section{Resumo}

Dependendo da forma como os conflitos interpessoais são abordados e resolvidos, podem se tornar oportunidades de aprendizagem e de maior qualidade às relações, ou resultar em danos aos envolvidos, sendo identificadas três tendências principais em suas resoluções: assertivas, agressivas e submissas. Dentre os fatores que podem influenciar na adoção de um estilo de resolução, em detrimento de outro, é indicada a 
mídia televisiva. Nesse sentido, teve-se como objetivo identificar os estilos de resolução de conflitos mais presentes nos desenhos animados Pica-Pau e Bob Esponja. Foram gravados quarenta minutos de episódios de cada um desses desenhos, realizando-se observação, registro e mensuração dos comportamentos veiculados. Os resultados demonstraram que nos desenhos animados analisados existiam inúmeras situações de conflitos, e que os estilos com maior ocorrência foram os agressivos e submissos. Foi destacada a importância de se reconhecer e compreender aquilo que é veiculado na televisão, e de refletir e discutir seus conteúdos com as crianças, na família e na escola.

Palavras-chave: Televisão. Desenvolvimento infantil. Conflitos.

\begin{abstract}
Depending on the way interpersonal conflicts are approached and solved, they may turn into learning opportunities and provide a higher quality to the interpersonal relationship, or result as a damage to the involved individuals, identifying three main tendencies in their resolutions: assertive, aggressive and submissive. Among the factors that may influence the adoption of a style of resolution over another, the $T V$ media is indicated. This way, the objective was to identify the most often styles of conflict resolution in the cartoons Woodpecker and Sponge Bob. Forty minutes of episodes of each cartoon were recorded for further observation, registering and measuring of the conveyed behavior. The results showed that in the cartoons analyzed there were numerous situations of conflict and that the styles with higher occurrence were the aggressive and the submissive ones. The importance of recognizing what is shown on TV, reflection, and discussion of their contents with the kids, in a family environment and at school were outlined.
\end{abstract}

Keywords: Television. Child development. Styles of conflict resolution.

\title{
Introdução
}

No cotidiano, os conflitos interpessoais estão presentes nos diferentes contextos no ambiente de trabalho, na família, na escola, dentre outros -, sendo não só inevitáveis e intrínsecos aos relacionamentos, mas necessários às relações e aos envolvidos, tendo em vista que, em algumas situações, podem propiciar aprendizagens e maior qualidade aos relacionamentos. No entanto, dependendo da forma como são concebidos, abordados e resolvidos, os conflitos podem ser geradores de danos aos envolvidos e à sociedade como um todo, segundo Vicentin (2009).

Deluty $(1979,1981,1985)$ aponta que, nas situações de conflitos, os indivíduos podem lançar mão das seguintes estratégias de resolução: agressiva, submissa e assertiva. A primeira estratégia, que tem como característica o comportamento agressivo, consiste no enfrentamento da situação de conflito, porém, com o uso da violência, coerção e não consideração dos direitos e deveres do outro. No estilo submisso, não há o enfrentamento do conflito, pois o indivíduo procura, por meio da fuga ou esquiva, não se deparar com a situação, ocorrendo muitas vezes a negação da mesma. Além disso, considera os direitos e sentimentos de outrem em prejuízo dos próprios. O estilo assertivo, por sua vez, tem como característica o enfrentamento do conflito, no entanto, sem o uso da coerção ou imposições, já que leva em conta os direitos, opiniões e sentimentos dos outros, assim como os próprios. Segundo Vicentin (2009), além dessas três estratégias descritas por Deluty $(1979,1981,1985)$ podem ser encontrados os estilos de caráter misto (assertivo-submisso, 
submisso-agressivo e assertivo-agressivo), naquelas situações em que são apresentadas mais de uma forma de resolução em um mesmo conflito.

Vicentin (2009) esclarece que não é recomendável utilizar classificações para as pessoas, rotulando-as como agressivas, submissas ou assertivas. O que se está em pauta é qual o estilo que, predominantemente, é usado nas diferentes circunstâncias. Ainda conforme a autora, cada um dos estilos pode resultar em implicações diferentes. No estilo agressivo, as consequências podem reverter em danos para ambas as partes envolvidas no conflito. Para Leme (2004), um risco que acomete os indivíduos que empregam tendências agressivas é o isolamento social, gerando um círculo vicioso em que o sentimento negativo despertado pela rejeição do outro gera a raiva, que, por sua vez, leva a reações agressivas e, em decorrência, a mais rejeição e isolamento. De acordo com Vicentin (2009), também se corre o risco de, em alguma situação de conflito, encontrar-se alguém com o mesmo estilo de resolução e, assim, redundar em violência e em danos à integridade física dos envolvidos. Há as situações que não chegam ao tipo de resolução agressivo, pelo fato de uma das partes reagir de maneira submissa. As consequências dessa forma de agir não são explícitas e, muitas vezes, por não envolver o confronto, esse tipo de conduta é incentivado por pais e educadores. Não obstante, segundo Vicentin (2009), as pessoas que adotam esse estilo podem se sentir frustradas, ansiosas e infelizes, por não atingirem seus objetivos e sempre abrirem mão de seus desejos.

O estilo assertivo é o mais desejável, porém, nem sempre o mais frequente. Favorece a autonomia moral, pois, na forma como o conflito se encerra, pode não prevalecer suas opiniões, mas o que realmente importa é a livre expressão e a possibilidade de trocas ( $\mathrm{Vi}$ centin, 2009). Nesse contexto, o conflito é visto como positivo, uma vez que fornece oportunidades de descentração, coordenação de perspectivas e busca de soluções mais justas. Por tal motivo, Leme (2004) indica o comportamento assertivo como o mais evoluído, em função das coordenações cognitivo-afetivas que solicita.

Em relação às variáveis que podem auxiliar as diferentes tendências de resolução de conflitos, no que diz respeito à manifestação da agressividade, Leme (2004) enfatiza que, apesar de serem encontrados indícios de componentes biológicos associados à adaptação, outros fatores estão presentes, como aspectos vinculados à personalidade, expectativas socioculturais, aspectos circunstanciais, além de variáveis relacionadas à cultura familiar e à exposição à mídia violenta. A exposição à violência representa um risco importante, especialmente no início da vida, pois estimularia a formação desse tipo de padrão para a resolução de novos conflitos, decorrentes da organização, abstração e retenção de experiências recorrentes dessa natureza (Leme, 2004).

Dando enfoque ao papel do meio, faz-se referência, dentro da proposta da presente pesquisa, àqueles vinculados aos elementos da cultura, dentre eles os meios de comunicação, sobre cuja parte vários autores reconhecem, no desenvolvimento psicológico dos indivíduos, principalmente na formação de diferentes tipos de valores (Garcez, 2010; Kane, Taub, \& Hayes, 2000; Moreno, 2008; Prates, 2004; Ramírez, 2007; Vidigueira, 2006), pois segundo esses autores a mídia é um importante meio de formação de valores.

Para Ramírez (2007), os programas infantis têm mais atos violentos do que os programas adultos. Ou seja, as crianças estão muito expostas a esse tipo de influência, mesmo que só assistam a programas destinados a elas, já que, segundo Rosenkoetter, Rosenkoetter e Acock (2009), 70\% dos programas produzidos para crianças contêm violência. Nesses programas, muitas vezes, é veiculado que a melhor maneira de resolver um problema é 
pela violência, comportamento que pode trazer ainda certo status para o personagem que o pratica (Camino et a., 1994; Erausquim, Matilla, \& Vásquez, 1983; Linder \& Gentile, 2009; Rosenkoetter et al., 2009).

Sobre as repercussões disso, Blumberg, Bierwirth e Schwartz (2008) apontam que a exposição a conteúdos agressivos tem contribuído para reforçar os pensamentos e comportamentos agressivos das crianças. Linder e Gentile (2009), Pereira Júnior (2008) e Belloni (2001) salientam que as crianças passam a admitir a violência, transmitida pela televisão, como normativa e aceitável, pois, como as informações são trazidas muito rapidamente, ficam apenas no plano superficial, das aparências, sem dar tempo ao telespectador de refletir sobre as situações; além disso, não só a agressão física deve ser levada em conta, mas também a agressão verbal e indireta, que, aliás, aparece em grande número nos programas televisivos.

Conforme Silva, Fonseca e Lourenço (2002), diversos estudos têm destacado três tipos de efeitos negativos, gerados pela exposição à violência televisiva: aqueles que incidem na utilização, por parte dos telespectadores, de atitudes favoráveis à agressão na resolução de conflitos; a dessensibilização, gerando a banalização da violência, já que as pessoas ficam menos sensíveis a ela; e a síndrome do mundo paranoide, pela qual a televisão pode alterar a percepção que se tem do mundo real. Por outro lado, esses mesmos autores apresentam alguns estudos que defendem que a violência na televisão pode ter um efeito positivo, como o de catarse, uma vez que pode propiciar de modo substitutivo o alívio de necessidades agressivas. Os estudos descritos por Biaggio (2007) demonstram que há evidências de que a exposição a modelos agressivos na televisão favorece a manifestação de comportamentos dessa natureza pelas crianças telespectadoras. Em contrapartida, a autora ressalta a existência de pesquisas que negam haver uma relação direta entre os conteúdos televisivos e o comportamento da criança, uma vez que não a tomam como um receptor passivo, mas capaz de interpretação e avaliação do que se está sendo veiculado. Além disso, a televisão não deve ser considerada como um fenômeno isolado, porque ela não somente influencia, mas também é influenciada pelos contextos sociais.

Nascimento Silva (2009) confirma esses dados ao revelar, em sua investigação sobre as concepções e percepções de crianças do Ensino Fundamental de uma escola pública, em relação às cenas violência física a que assistiam na televisão, que a maioria das participantes reconhece e aproxima as cenas de violência presentes nos programas televisivos com aquelas que encontram nos diferentes espaços do cotidiano: escola, família e bairro onde residem. A autora verificou, ainda, que as crianças possuem autonomia no que diz respeito às escolhas daquilo que querem ver na televisão, estando, por conseguinte, expostas aos diferentes tipos de violência veiculados. Ao buscar entender a manifestação da violência no espaço escolar, a autora salienta que poderia afirmar que as crianças reproduzem as cenas a que assistem na televisão, tal como fazem as teorias da aprendizagem. No entanto, ela adverte que é necessário um olhar de caráter multidimensional, no qual a compreensão das relações dos conteúdos difundidos pela televisão e as condutas dos indivíduos deve contemplar os aspectos socioculturais, uma vez que as estruturas e sistemas dos quais as pessoas fazem parte colaboram na mediação e significação daquilo a que estão expostas - no caso a mídia televisiva.

A pesquisa de Baptistella (2001) comprova que a criança não é uma telespectadora passiva diante do que é veiculado na televisão. Seu estudo, embasado na teoria de Piaget, buscou compreender as representações de crianças sobre a função da televisão e em rela- 
ção ao conteúdo de determinado comercial televisivo. Os resultados confirmaram o existente na literatura de que há uma evolução na compreensão das crianças, conforme o aumento da idade e do nível cognitivo. As crianças menores e em estágios anteriores de desenvolvimento cognitivo demonstram dificuldades em entender o que é transmitido na televisão, em reunir os elementos que compõem o enredo apresentado, fazer relações entre eles, recordando apenas pedaços daquilo que foi visto; além disso, não conseguem discriminar a mensagem central e destacá-la dos conteúdos periféricos, não assimilando de forma global a função da televisão e daquilo que veicula. Com a progressão da idade e do nível cognitivo, a compreensão da criança vai aumentando, no entanto, sem garantias de uma atitude crítica.

Com base nos estudos apresentados (Camino et al., 1994; Erausquim et al., 1983; Belloni, 2001; Ramírez, 2007; Blumberg et. al., 2008; Pereira Júnior, 2008; Linder \& Gentile, 2009; Rosenkoetter et al., 2009) é possível constatar que a questão da violência nos programas infantis e as implicações da exposição da criança a conteúdos dessa natureza são aspectos que têm sido investigados. No entanto, a presente pesquisa traz como contribuição científica o escopo de se voltar para a relação entre televisão e conflitos interpessoais, de forma a ultrapassar a categoria da violência na análise das situações que os enredos que compõem os programas infantis apresentam. Fundamentando-se nos referenciais de Deluty (1979, 1981, 1985), Leme (2004) e Vicentin (2009) tem-se o propósito de examinar não somente a presença de estilos agressivos de resolução de conflitos, como as tendências submissas e assertivas. A análise que se propõe pode contribuir de modo a favorecer uma melhor compreensão sobre o conteúdo veiculado pela televisão e seu papel na reprodução elou constituição dos diferentes estilos de resolução de conflitos interpessoais que se manifestam nos diferentes contextos.

Assim, este estudo tem como objetivo geral identificar as tendências de resolução de conflitos mais presentes em episódios de dois desenhos animados. São objetivos específicos: observar e registrar, nas situações de conflitos, os tipos de estratégias de resolução empregados pelos diferentes personagens dos desenhos, no geral, e pelos personagens preferidos, de acordo com categorias predefinidas.

\section{Método}

Para a escolha dos desenhos animados analisados nesta pesquisa, teve-se como base o estudo de Oliveira (2011), realizado com 162 crianças de seis a onze anos, do $1^{\circ}$ ao $5^{\circ}$ ano do Ensino Fundamental de uma escola pública do interior paulista. Os participantes da pesquisa responderam um questionário sobre suas preferências televisivas. Neste, principalmente dois desenhos (Pica-Pau e Bob Esponja) foram indicados pelos participantes como os mais assistidos e preferidos. Além disso, constatou-se que os personagens, apontados pelas crianças como os seus preferidos, foram o próprio Pica-Pau - no caso do PicaPau - e o Bob Esponja e o Patrick - no do Bob Esponja.

Fundamentado na saturação dos tipos de comportamentos ocorrentes, foi determinado um tempo de 40 minutos de gravação para cada desenho selecionado. Os episódios dos desenhos foram gravados na sequência em que foram veiculados na TV aberta, durante o mês de setembro de 2010. Como a duração de cada episódio variou conforme o dese- 
nho, foram gravados oito episódios do Pica-Pau (1946, 1952, 1956, 1957, 1960, 1968, 1970, 1971) e quatro do Bob Esponja (2005a, 2005b, 2005c, 2007).

Em continuidade, foi empregada a técnica de Observação Sistemática, que consiste na observação, registro e mensuração de eventos, com base em procedimentos padronizados (Vianna, 2007). Foi utilizada a técnica Registro de Eventos, em que são definidos, mediante categorias, e contados, em termos de frequência, os comportamentos a serem observados (Fagundes, 1999). As categorias foram definidas segundo o apresentado por Deluty (1979, 1981, 1985), Leme (2004) e Vicentin (2009), a saber: Estilo de Resolução Agressivo: há o enfrentamento da situação de conflito, no entanto, utilizando-se de coerção, de violência e desconsiderando-se os direitos, ideias e sentimentos dos outros; Estilo de Resolução Submisso: tem como característica o não enfrentamento do conflito, mediante a fuga ou esquiva, e os direitos e sentimentos dos outros se sobrepõem aos próprios; e Estilo de Resolução Assertivo: envolve o enfrentamento da situação, buscando-se a defesa dos próprios direitos, porém, sem o uso da coerção e levando-se em consideração os sentimentos, opiniões e direitos dos outros. Além desses estilos, foram observados os mistos (Vicentin, 2009): submisso-agressivo; assertivo-submisso e assertivo-agressivo, que abarcaram situações em que houve mais de uma forma de resolução em um mesmo conflito.

Com o intuito de garantir a confiabilidade dos registros das observações realizadas e de identificar a pertinência dos estilos usados no presente estudo, foram realizadas sessões de treinamento e o cálculo do Índice de Concordância, que consiste, conforme Fagundes (1999), na quantificação da concordância do registro realizado por dois observadores, que avaliam e registram os mesmos eventos, de maneira independente. Posteriormente, seus registros são comparados, com o propósito de se averiguar em que medida há concordância entre eles e até que ponto se pode confiar nas informações que registraram. Para a realização do emprego do Índice de Concordância, a pesquisadora principal contou com a participação de mais um pesquisador, com conhecimento na área. O Índice de Concordância obtido foi de aproximadamente 70\%, valor considerado satisfatório (Fagundes, 1999).

\section{Resultados}

Na observação e registro dos episódios, os dados foram examinados a fim de identificar os estilos de resolução de conflitos mais presentes nos comportamentos encontrados. Essas tendências foram obtidas calculando-se a frequência e a porcentagem dos estilos existentes nos desenhos, conforme os padrões pré-definidos: agressivo, submisso, assertivo, agressivo-submisso, agressivo-assertivo e assertivo-agressivo. A análise foi feita em relação aos personagens, no geral, e no referente aos personagens preferidos. Na Tabela 1, são apresentados os registros concernentes aos oito episódios do desenho Pica-Pau, objetos dessa investigação. 
Tabela 1- Estilos de resolução de conflitos observados e registrados no desenho Pica-Pau

\begin{tabular}{l|c|c|c|c}
\hline \multirow{2}{*}{$\begin{array}{l}\text { Estilos de resolução } \\
\text { de conflitos }\end{array}$} & \multicolumn{2}{|l|}{ Personagens no geral } & \multicolumn{2}{l}{ Personagem preferido: Pica-Pau } \\
\cline { 2 - 5 } & Frequência & Porcentagem & Frequência & Porcentagem \\
\hline 1- Agressivo & 85 & $70,24 \%$ & 27 & $65,85 \%$ \\
2- Submisso & 14 & $11,57 \%$ & 2 & $4,87 \%$ \\
3- Assertivo & 11 & $9,09 \%$ & 6 & $14,63 \%$ \\
$\begin{array}{l}\text { 4- Agressivo- } \\
\begin{array}{l}\text { Submisso } \\
\text { 5- Agressivo- }\end{array}\end{array}$ & 3 & $2,47 \%$ & 1 & $2,43 \%$ \\
$\begin{array}{l}\text { Assertivo } \\
\text { 6- Submisso- } \\
\text { Assertivo }\end{array}$ & 2 & $1,65 \%$ & 2 & $4,87 \%$ \\
\hline Total & 6 & $4,95 \%$ & 3 & $7,31 \%$ \\
\hline
\end{tabular}

Como pode ser visualizado na Tabela 1, dos 121 estilos de resolução de conflitos que encontrados nos diferentes episódios do desenho Pica-Pau, 85 (70,24\%) foram do estilo agressivo, predominância que também se manteve no personagem preferido, em que, em 41 dos estilos registrados, 27 (65,85\%) foram do agressivo. As estratégias submissas apareceram 14 vezes $(11,57 \%)$, abordando o desenho no geral, porém, no personagem preferido, esse tipo de estratégia esteve presente apenas duas vezes $(4,87 \%)$. No que concerne às estratégias assertivas, elas compareceram no desenho 11 vezes, representando 9,09\% dos estilos apresentados. Já o personagem Pica-Pau agiu de forma assertiva em seis momentos, atingindo o percentil de 14,63\%. Quanto aos estilos mistos, as frequências obtidas foram: agressivo-submisso, $3(2,47 \%)$ no desenho e $1(2,43 \%)$ no personagem preferido; agressivo-assertivo, $2(1,65 \%)$ no desenho e $2(4,87 \%)$ no personagem preferido; e submisso-assertivo, $6(4,95 \%)$ no desenho e $3(7,31 \%)$ no personagem preferido. $\mathrm{Na}$ Tabela 2, seguem os dados atinentes aos quatro episódios do desenho Bob Esponja analisados.

Tabela 2- Estilos de resolução de conflitos observados e registrados no desenho Bob Es-

\begin{tabular}{|c|c|c|c|c|}
\hline \multirow[t]{2}{*}{$\begin{array}{l}\text { Estilos de resolução de } \\
\text { conflitos }\end{array}$} & \multicolumn{2}{|c|}{ Personagens no geral } & \multicolumn{2}{|c|}{$\begin{array}{l}\text { Personagens preferidos: Bob } \\
\text { Esponja e Patrick }\end{array}$} \\
\hline & Frequência & Porcentagem & Frequência & Porcentagem \\
\hline 1- Agressivo & 20 & $32,78 \%$ & 13 & $33,33 \%$ \\
\hline 2- Submisso & 29 & $47,54 \%$ & 16 & $41,02 \%$ \\
\hline 3- Assertivo & 10 & $16,39 \%$ & 9 & $23,07 \%$ \\
\hline 4- Agressivo- & & & & \\
\hline Submisso & 0 & $0 \%$ & 0 & $0 \%$ \\
\hline 5- Agressivo- & & & & \\
\hline Assertivo & 0 & $0 \%$ & 0 & $0 \%$ \\
\hline 6- Submisso-Assertivo & 2 & $3,27 \%$ & 1 & $2,56 \%$ \\
\hline Total & 61 & $100 \%$ & 39 & $100 \%$ \\
\hline
\end{tabular}


Com base na Tabela 2, pode-se identificar que prevaleceu no desenho em pauta o estilo submisso de resolução de conflitos, com 29 (47,54\%) ocorrências, acompanhado pelo comportamento agressivo, com frequência de 20 (32,78\%). Em seguida, apareceram o estilo assertivo, com 10 (16,39\%) ocorrências, e o estilo submisso-assertivo, com apenas duas $(3,27 \%)$ ocorrências. Os estilos agressivo-submisso e agressivo-assertivo não estiveram presentes nesse desenho. Nos personagens preferidos (Bob Esponja e Patrick), observa-se a repetição dessas tendências, comparecendo o estilo submisso em $16(41,02 \%)$ das vezes, seguido do agressivo, com frequência 13 (33,33\%), e, posteriormente, do assertivo, com frequência $9(23,07 \%)$. Também esteve presente nos personagens preferidos o estilo submisso-assertivo, com uma (2,56\%) ocorrência.

Com base nos resultados explicitados, é possível afirmar que, nos desenhos analisados, apareceram com maior frequência os três estilos de resolução denominados puros (Leme, 2004; Vicentin, 2009), com destaque para as tendências agressivas e submissas, enquanto os estilos mistos estiveram presentes em menor escala.

No desenho Pica-Pau, em todos os episódios examinados, compareceram, e de forma predominante, estilos agressivos de resolução de conflitos, não apenas no desenho como um todo, mas também no personagem preferido. Para ilustrar, segue uma situação ocorrida no episódio 2 (Pica-Pau, 1971), em que o personagem Pica-Pau resolve descansar em uma torre de relógio. Quando dá certa hora, o sino do relógio começa a tocar, PicaPau acorda furioso e coloca uma chave nas engrenagens, que faz o relógio parar. Com diversas reclamações da população, o prefeito da cidade liga para um técnico e este vai para a torre arrumar o relógio. Chegando lá, ele retira a chave e, quando está descendo as escadas, o Pica-Pau coloca novamente a chave nas engrenagens: o técnico volta e a retira. Pica-Pau aparece e recoloca a chave, ficando ambos nesse embate, até que o técnico pega o Pica-Pau e o joga de cima da torre. Pica-Pau sobe novamente a torre e, quando chega lá em cima, vê que o técnico está descendo pelo balanço para arrumar as horas do relógio. Trava-se o seguinte diálogo: "Pica-Pau: - Ei, Seu Chucrute, o que está fazendo? Técnico: Seu idiota, vai embora!" (Pica Pau, 1971). Pica-Pau, no mesmo instante em que é xingado, retira o gancho onde o balanço está pendurado e assim faz com que o técnico caia sobre os ponteiros do relógio; não satisfeito, vai ao regulador de velocidade dos ponteiros e o coloca no máximo, levando o técnico a ficar girando pendurado no relógio, até que seja arremessado longe dali.

Está explícito, nessa cena, o estilo agressivo dos personagens, não só do Pica-Pau, mas também do técnico, de resolver a situação. Na maior parte do fato relatado, não houve uma tentativa de diálogo, no intuito de favorecer um entendimento entre os personagens, nem ao menos um sabia o que o outro estava fazendo ali. Em certo momento, Pica-Pau tenta conversar, ao perguntar o que o técnico estava fazendo, mas, diante de sua resposta, ele parte para um desfecho de estilo agressivo e vingativo.

Ainda em relação ao desenho Pica-Pau, os motivos pelos quais os conflitos se deram, ao longo dos oito episódios analisados, foram, em sua maioria, de direito à propriedade, ou seja, o conflito central era baseado na disputa por espaço ou objeto, porém, a partir desse tipo de conflito central, surgiam, no desenrolar da trama, outros motivos desencadeadores e perpetuadores de conflitos, como, principalmente, a agressão física e a verbal. Como exemplo pode ser considerado o episódio 1 (Pica Pau, 1968), no qual João Pilantra se considera dono da cidade e não permite que ninguém entre nela com outro 
cavalo. Pica-Pau, porém, aparece com o cavalo Pé de Pano e, assim, cria um conflito com João Pilantra, que tenta resolvê-lo com agressões verbais e físicas. Em face dessa situação, Pica-Pau reage com trapaças, mentiras e agressões físicas e verbais.

Quanto ao desenho Bob Esponja, pode-se verificar que o estilo submisso foi o mais veiculado, seja considerando os personagens do desenho, no geral, seja por parte dos personagens apontados como os preferidos. No episódio 1 (Bob Esponja, 2007), por exemplo, Bob Esponja, acreditando que Patrick tivesse roubado sua rede de pescar água viva, acusao desse fato; Patrick, embora inocente, não argumenta com o amigo e se esquiva da situação, decidindo ir embora da Fenda do Biquíni, cidade aquática onde moram. No episódio 4 (Bob Esponja, 2005a), Patrick recebe um comunicado informando que ele é de descendência real; a partir desse momento, ele passa a exigir de todos à sua volta que lhe obedeçam. Em uma das situações, um peixe sai do restaurante do Sr. Siriguejo com um hambúrguer nas mãos, Patrick o intercepta, exigindo que lhe dê o lanche. Em um primeiro momento, Bob Esponja demonstra dúvida em relação à exigência de Patrick, mas, diante do questionamento de Patrick, ele concorda com ele e também exige que o peixe o entregue a $\mathrm{Pa}$ trick. Percebe-se, nessa cena, que, mesmo que Bob Esponja ache errado que Patrick tome o lanche dos outros, ele não se opõe quando o amigo o pressiona, mas simplesmente prefere concordar com o outro, para não contrariá-lo, a lhe explicar que o que ele estava fazendo não era certo nem tão pouco justo.

Os motivos dos conflitos encontrados nesse desenho foram, em sua maior parte, oriundos de conflitos verbais e em função do direito à propriedade (disputa por espaço e/ou objeto).

\section{Discussões}

No geral, considerando os dois desenhos analisados, verifica-se que as causas geradoras de conflitos estão entre aquelas indicadas por Vinha (2003) e as encontradas na pesquisa de Licciard (2010), em que os mais citados são os conflitos devido ao direito à propriedade, em que há disputa por espaço e/ou objeto; a ação provocativa intencional e a ação provocativa não-intencional; a agressão física e/ou verbal; e a rejeição, em que há a exclusão nas elações ou atividades. Estando presentes neste estudo, sobretudo, os motivos de disputa por objeto e espaço.

A presente pesquisa, além de confirmar os estudos de diversos autores que também identificam a ocorrência de comportamentos violentos nos programas infantis (Erausquim et al., 1983; Belloni, 2001; Silva et al., 2002; Biaggio, 2007; Ramírez, 2007; Pereira Júnior, 2008; Rosenkoetter et al., 2009; Linder \& Gentile, 2009; Chávez \& Virrueta, 2009), demonstra que os desenhos analisados são repletos de situações de conflitos interpessoais, para cuja resolução, além de reações que retratam a violência, é evidente o uso da coação e consequente submissão entre os envolvidos, com relações marcadas pela autoridade, pela coação, pelo respeito unilateral e a expiação. Dificilmente, nas situações retratadas nos episódios dos desenhos, busca-se o entendimento consensual, a negociação e formas respeitosas de se resolver os problemas entre os personagens, de sorte a se restabelecer o equilíbrio em suas relações. Assim, verifica-se que os tipos de estratégias de resolução veiculados nesses desenhos resultam muito mais em danos, tanto físicos e psicológicos ao 
envolvidos, do que em oportunidades de aprendizagem, tal como descrito por Vinha (2003), Vicentin (2009) e Licciardi (2010).

Esses dados apontam para a necessidade de se analisar sua repercussão no desenvolvimento infantil. Como mencionado anteriormente, vários estudos que procuram entender o efeito dos modelos transmitidos na televisão, para a formação da criança, indicam uma associação positiva entre aquilo que é veiculado nos programas infantis e os comportamentos da criança (Belloni, 2001; Silva et al., 2002; Biaggio, 2007; Blumberg et al., 2008; Pereira Júnior, 2008; Linder \& Gentile, 2009).

De acordo com Leme (2004), pesquisas têm revelado que os funcionamentos psicológicos valorizados nas diferentes culturas comparecem igualmente nas práticas de socialização, incentivando determinado estilo de resolução, em detrimento de outros. Assim, a cultura possui um papel relevante na aprendizagem de estilos de resolução de problemas interpessoais, uma vez que os sistemas de valores oferecerão significados às interações realizadas nos grupos. Não obstante, não deve ser feita uma leitura de determinação dos elementos da cultura sobre o indivíduo, já que este pode desempenhar um papel ativo, seja como transformador de si mesmo, seja da própria cultura.

Com base no exposto e na afirmação de Biaggio (2007), para quem a televisão não deve ser considerada um fato separado, porque não somente tem o poder de influenciar, mas também é influenciada pelos contextos sociais, é possível indagar se os programas examinados neste estudo e a televisão, de uma forma geral, não estariam apenas reproduzindo os estilos que mais comparecem nas situações da vida cotidiana. Nas pesquisas realizadas com crianças e adolescentes (Leme, 2004; Vicentin, 2009), os resultados indicam que as tendências mais frequentes são as submissas e agressivas, ou seja, as mesmas observadas nos desenhos objeto deste estudo. Vicentin (2009) aponta especialmente a família e a escola como instituições que valorizam e contribuem mais para a formação de estilos submissos e agressivos, do que assertivos. Nas pesquisas de Vinha (2003) e Frick (2011), é indicada, também, a contribuição do ambiente escolar para o incentivo de formas mais submissas, coercitivas e agressivas de se relacionar.

Assim, da mesma maneira que não se pode sustentar que haja uma sobredeterminação da cultura televisiva sobre a sociedade, não é possível aludir a uma unilateralidade entre o transmitido na televisão e a formação da criança, especialmente se considerar que as ações não são decorrentes da aprendizagem de modelos, mas fruto de uma construção interna elaborada pelo indivíduo, a partir de suas vivências e interações com o meio. Vicentin (2009) ressalta que, apesar da influência de modelos na manifestação de diferentes estilos de resolução de conflitos pela criança, deve-se considerar a maneira como ela organiza internamente as situações vivenciadas.

Nascimento e Silva (2009), ao enfatizar a necessidade de se compreender os efeitos da mídia televisiva de forma multidimensional e em seus aspectos socioculturais, dá destaque ao papel da família e da escola na ressignificação daquilo que as crianças assistem. Nesse mesmo sentido, Baptistella (2009), aponta à corresponsabilidade do Estado, da escola e da família nas questões televisivas: o Estado, promovendo discussões e políticas de proteção à criança e ao adolescente nesse âmbito; a escola, apropriando-se dos estudos na área, fomentando debates e programas de intervenção com e na comunidade escolar; e a família, estando atenta àquilo que é veiculado na televisão e buscando seus direitos a respeito. 
Em concordância com Baptistella (2001), ressalta-se a importância de se trabalhar sistematicamente os conteúdos veiculados na televisão com as crianças, incentivando-se uma postura reflexiva diante das situações apresentadas. E a escola, poderia auxiliar nessa função de transformar a criança em um telespectador crítico e com uma maior compreensão quanto aos conteúdos e função da televisão, inclusive possibilitando, nas discussões sobre os conteúdos televisivos, deflagrar questões emergentes do cotidiano e da sociedade.

\section{Considerações finais}

Esta pesquisa teve como objetivo identificar as tendências de resolução de conflitos mais presentes em episódios dos desenhos animados Pica-Pau e Bob Esponja, manifestadas por seus diferentes personagens e pelos personagens tidos como preferidos. Os resultados demonstraram que existem inúmeras situações de conflitos nos desenhos analisados, comparecendo mais os estilos puros de resolução de conflitos - agressivo, submisso e assertivo - do que os estilos mistos. No desenho Pica-Pau verificou-se predominantemente o estilo agressivo de resolução de conflitos, e no Bob Esponja o estilo submisso. Esses estilos estiveram presentes tanto no geral dos personagens de cada desenho, como naqueles apontados pelas crianças como seus preferidos.

A despeito de os estudos apontarem para a influência dos modelos veiculados na televisão na formação infantil, há o entendimento de que a criança não é passiva em face dos conteúdos televisivos, assim como seu desenvolvimento dependerá de diversos fatores internos e externos. A mídia televisiva seria um desses fatores, embora não isolado e único, mas que também deve ser considerado. Não obstante, este estudo tem como limite restringir-se aos conteúdos transmitidos pelos programas televisivos analisados. Para que seja possível verificar o efeito desses na formação sociomoral das crianças que os assistem sugere-se a realização de estudos de delineamento experimental, para que, então, seus efeitos possam ser rigorosamente apreciados.

Os conflitos são inevitáveis e necessários ao desenvolvimento e relacionamentos, todavia, a forma como eles são resolvidos nas relações do cotidiano e transmitidos na televisão deveria servir de oportunidade a uma leitura crítica e reflexiva. Destaca-se, assim, não só a importância de reconhecer e compreender, de forma crítica, aquilo que é veiculado na televisão, mas principalmente de utilizar seu conteúdo como assunto de reflexão e discussão com as próprias crianças. Dependendo da posição que a criança, a escola e a família assumem, diante da televisão, os conteúdos transmitidos podem ser modelos a ser imitados e reproduzidos ou, de modo oposto, objetos de discussões e reflexões que promovam desequilíbrios, trocas de ponto de vista e, consequentemente, desenvolvimento.

\section{Referências}

Baptistella, E. C. F. (2001). A compreensão do conteúdo de um comercial televisivo na infância. Dissertação de Mestrado, Faculdade de Educação da Universidade Estadual de Campinas, Campinas. 
Baptistella, E. C. F. (2009). A concepção de pais e professores sobre a educação para a mídia televisiva na escola. Tese de Doutorado, Faculdade de Educação da Universidade Estadual de Campinas, Campinas.

Belloni, M. L. (2001). O que é mídia-educação. (Coleção Polêmicas do Nosso Tempo). Campinas, SP: Autores Associados.

Biaggio, A. M. B. (2007). Psicologia do desenvolvimento (19a ed.). Petrópolis: Vozes, 2007.

Blumberg, F. C., Bierwirth, K. P., \& Schwartz, A. J. (2008, August). Does Cartoon Violence Beget Aggressive Behavior in Real Life? An Opposing View. Early Childhood Educ J, 36, 101-104.

Bob Esponja/SpongeBob SquarePants. (2005a). Reinado de idiotas. Estados Unidos: Nickelodeon Animation Studios. Série de desenho animado transmitida pela emissora Rede Globo, Brasil, em setembro 2010.

Bob Esponja/SpongeBob SquarePants. (2005b). O ladrão cor-de-rosa. Estados Unidos: Nickelodeon Animation Studios. Série de desenho animado transmitida pela emissora Rede Globo, Brasil, em setembro 2010.

Bob Esponja/SpongeBob SquarePants. (2005c). Aniversário da baleia. Estados Unidos: Nickelodeon Animation Studios. Série de desenho animado transmitida pela emissora Rede Globo, Brasil, em setembro 2010.

Bob Esponja/SpongeBob SquarePants. (2007). O ladrão cor-de-rosa. Estados Unidos: Nickelodeon Animation Studios. Série de desenho animado transmitida pela emissora Rede Globo, Brasil, em setembro 2010.

Camino, C., Batista, L., Reis, R., Rique, J., Luna, V., \& Cavalcanti, M. (1994). Transmissão de Valores Morais em Personagens de TV. Psicologia Reflexão e Crítica, 7 (1), 29-46.

Chávez, M. C. M., \& Virrueta, E. R. (2009, February/March). La violencia en los dibujos animados norteamericanos y japoneses: su impacto en la agresividad infantil. Alternativas en Psicología, XIV (20), 26-34.

Deluty, R. H. (1979). Children's Action Tendency Scale: A self-report measure of aggressiveness, assertiveness, and submissiveness in children. Journal of Consulting and Clinical Psychology, 47 (6), 1061-1071.

Deluty, R. H. (1981). Alternative-thinking ability of aggressive, assertive, and submissive children. Cognitive Therapy and Research, 5 (3), 309-312.

Deluty, R. H. (1985). Cognitive mediation of aggressive, assertive and submissive behavior in children. International Journal of Behavior Development, 8, 355-369.

Erausquim, M. A., Matilla, L., \& Vásquez, M. (1983). Os teledependentes. São Paulo: Summus.

Fagundes, A. J. F. M. (1999). Descrição, definição e registro de comportamento. São Paulo: Edicon. 
Frick, L. T. (2011). As relações entre os conflitos interpessoais e o bullying: um estudo nos anos iniciais do ensino fundamental de duas escolas públicas. Dissertação de Mestrado, Faculdade de Ciências e Tecnologia da Universidade Estadual Paulista, Presidente Prudente.

Garcez, A. M. (2010). Animar, se divertir e aprender: as relações de crianças com programas especialmente recomendados. Dissertação de Mestrado, Pontifícia Universidade Católica, Rio de Janeiro.

Kane, H. D., Taub, G. E., \& Hayes, B. G. (2000, September). Interactive media and its contribution to the construction and destruction of values and character. Journal of $\mathrm{Hu}$ manistic Counseling, Education and Development, 39(1), 56-63.

Leme, M. I. S. (2004). Resolução de conflitos interpessoais: interações entre cognição e afetividade na cultura. Psicologia: Reflexão e Crítica, 17(3), 367-380.

Licciardi, L. M. S. (2010). Investigando os conflitos entre as crianças na escola. Dissertação de Mestrado, Faculdade de Educação da Universidade Estadual de Campinas, Campinas.

Linder, J. R., \& Gentile, D. A. (2009, February). Is the television rating system valid? Indirect, verbal, and physical aggression in programs viewed by fifth grade girls and associations with behavior. Journal of Applied Developmental Psychology, 30, 286-297.

Moreno, G. L. (2008, July). La Transmisión de valores en los programas infantiles. Comunicar, 16(i31), 411-415.

Nascimento Silva, V. (2009). Violência, televisão e infância: um estudo de caso de alunos de uma escola pública de Monte Claros/MG. Dissertação de Mestrado, Universidade Estadual de Montes Claros, Montes Claros.

Oliveira, D. M. S. de. (2011). Televisão e formação moral: um estudo sobre os conteúdos sociomorais presentes nos desenhos animados. Trabalho de Conclusão de Curso, Faculdade de Filosofia e Ciências da Universidade Estadual Paulista, Marília.

Pereira Júnior, A. J. (2008). Impacto da violência midiática na formação da criança e do adolescente. Recuperado em 25 abril 2010, em http://www.univforum.org/pdf/xzimpacto_dapt.pdf.

Pica-Pau/Woody Woodpecker. (1946). Quem cozinha quem. Produção de: Walter Lantz. Estados Unidos: Universal Pictures. Série de desenho animado transmitida pela emissora TV Record, Brasil, em setembro 2010.

Pica-Pau/Woody Woodpecker. (1952). Nascido para picar. Produção de: Walter Lantz. Estados Unidos: Universal Pictures. Série de desenho animado transmitida pela emissora TV Record, Brasil, em setembro 2010.

Pica-Pau/Woody Woodpecker. (1956). Festival de cucos. Produção de: Walter Lantz. Estados Unidos: Universal Pictures. Série de desenho animado transmitida pela emissora TV Record, Brasil, em setembro 2010. 
Pica-Pau/Woody Woodpecker. (1957). O bandido do trem. Produção de: Walter Lantz. Estados Unidos: Universal Pictures. Série de desenho animado transmitida pela emissora TV Record, Brasil, em setembro 2010.

Pica-Pau/Woody Woodpecker. (1960). Pica-Pau pistoleiro. Produção de: Walter Lantz. Estados Unidos: Universal Pictures. Série de desenho animado transmitida pela emissora TV Record, Brasil, em setembro 2010.

Pica-Pau/Woody Woodpecker. (1968). Cidade de um cavalo só. Produção de: Walter Lantz. Estados Unidos: Universal Pictures. Série de desenho animado transmitida pela emissora TV Record, Brasil, em setembro de 2010.

Pica-Pau/Woody Woodpecker. (1970). Foca à solta. Produção de: Walter Lantz. Estados Unidos: Universal Pictures. Série de desenho animado transmitida pela emissora TV Record, Brasil, em setembro de 2010.

Pica-Pau/Woody Woodpecker. (1971). Hora de dormir. Produção de: Walter Lantz. Estados Unidos: Universal Pictures. Série de desenho animado transmitida pela emissora TV Record, Brasil, em setembro de 2010.

Prates, A. A. (2004). As representações de beleza transmitidas pelos filmes infantis. Recuperado em 31 agosto 2010, em http://www.psicopedagogia.com.br/artigos/artigo.asp?entrID=623.

Ramírez, J. M. (2007). Television y Violencia. Revista Latinoamericana de Psicología. $39(2), 327-349$.

Rosenkoetter, L. I., Rosenkoetter, S. E., \& Acock, A. C. (2009, March). Television violence: An intervention to reduce its impact on children. Journal of Applied Developmental Psychology. 30, 381-397.

Silva, C., Fonseca, E., \& Lourenço, O. (2002, Novembro). Valores Morais em Televisão: análise de uma série televisiva de grande audiência. Aná Psicológica, 20(4), 541-553.

Vianna, H. M. (2007). Pesquisa em educação: a observação. Brasília: Liber Livro.

Vicentin, V. F. (2009). Condições de vida e estilos de resolução de conflito entre adolescentes. Tese de Doutorado, Universidade de São Paulo. São Paulo.

Vidigueira, V. C. R. (2006). A influência da televisão no desenvolvimento sócio-emocional dos adolescentes. Trabalho de Conclusão de Curso, Faculdade de Ciências Humanas e Sociais da Universidade do Algarve, Portugal.

Vinha. T. P. (2003). Os conflitos interpessoais na relação educativa. Tese de Doutorado, Faculdade de Educação da Universidade Estadual de Campinas, Campinas.

Recebido/Received: 22/11/2012

Aprovado/Approved: 21/06/2014 